\title{
SOEP
}

SOEPpapers

on Multidisciplinary Panel Data Research

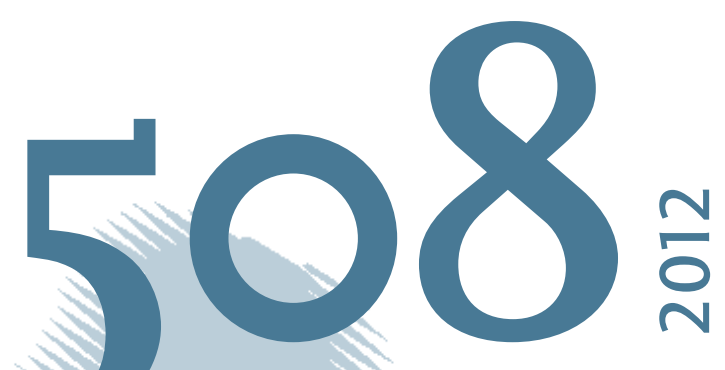

.

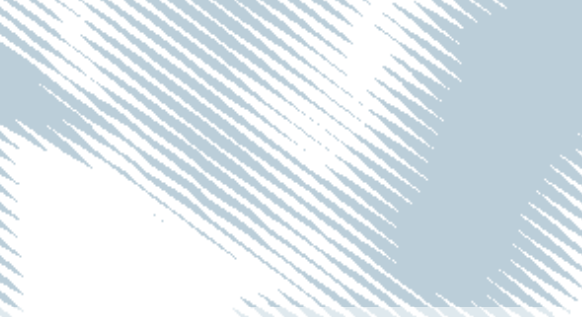

\section{Kick It Like Özil? \\ Decomposing the Native-Migrant Education Gap}

Annabelle Krause, Ulf Rinne, Simone Schüller 


\section{SOEPpapers on Multidisciplinary Panel Data Research}

at DIW Berlin

This series presents research findings based either directly on data from the German SocioEconomic Panel Study (SOEP) or using SOEP data as part of an internationally comparable data set (e.g. CNEF, ECHP, LIS, LWS, CHER/PACO). SOEP is a truly multidisciplinary household panel study covering a wide range of social and behavioral sciences: economics, sociology, psychology, survey methodology, econometrics and applied statistics, educational science, political science, public health, behavioral genetics, demography, geography, and sport science.

The decision to publish a submission in SOEPpapers is made by a board of editors chosen by the DIW Berlin to represent the wide range of disciplines covered by SOEP. There is no external referee process and papers are either accepted or rejected without revision. Papers appear in this series as works in progress and may also appear elsewhere. They often represent preliminary studies and are circulated to encourage discussion. Citation of such a paper should account for its provisional character. A revised version may be requested from the author directly.

Any opinions expressed in this series are those of the author(s) and not those of DIW Berlin. Research disseminated by DIW Berlin may include views on public policy issues, but the institute itself takes no institutional policy positions.

The SOEPpapers are available at

http://www.diw.de/soeppapers

\section{Editors:}

Jürgen Schupp (Sociology, Vice Dean DIW Graduate Center)

Gert G. Wagner (Social Sciences)

Conchita D'Ambrosio (Public Economics)

Denis Gerstorf (Psychology, DIW Research Director)

Elke Holst (Gender Studies, DIW Research Director)

Frauke Kreuter (Survey Methodology, DIW Research Professor)

Martin Kroh (Political Science and Survey Methodology)

Frieder R. Lang (Psychology, DIW Research Professor)

Henning Lohmann (Sociology, DIW Research Professor)

Jörg-Peter Schräpler (Survey Methodology, DIW Research Professor)

Thomas Siedler (Empirical Economics)

C. Katharina Spieß (Empirical Economics and Educational Science)

ISSN: 1864-6689 (online)

German Socio-Economic Panel Study (SOEP)

DIW Berlin

Mohrenstrasse 58

10117 Berlin, Germany

Contact: Uta Rahmann | soeppapers@diw.de 


\title{
Kick It Like Özil? Decomposing the Native-Migrant Education Gap
}

\author{
Annabelle Krause \\ $I Z A$ \\ Ulf Rinne \\ $I Z A$ \\ Simone Schüller \\ IZA
}

\begin{abstract}
We investigate second generation migrants and native children at several stages in the German education system to analyze the determinants of the persistent native-migrant gap. One part of the gap can be attributed to differences in socioeconomic background and another part remains unexplained. Faced with this decomposition problem, we apply linear and matching decomposition methods. Accounting for differences in socioeconomic background, we find that migrant pupils are just as likely to receive recommendations for or to enroll at any secondary school type as native children. Comparable natives, in terms of family background, thus face similar difficulties as migrant children. Our results point at more general inequalities in secondary schooling in Germany which are not migrant-specific.
\end{abstract}

JEL Classification: J15, J24, I21

Keywords: migration, education, human capital, Germany, tracking

Corresponding author:

Ulf Rinne

IZA

P.O. Box 7240

53072 Bonn

Germany

E-mail: rinne@iza.org

\footnotetext{
"Mesut Özil is a German soccer player with a Turkish family background. By the time this paper was prepared, he has been playing for Real Madrid and the German national team. The latter is often referred to as an example for the multi-ethnic German society and a successful integration of migrants therein. The data used in this paper were made available by the Socio-Economic Panel Study (SOEP) at the German Institute for Economic Research (DIW Berlin). Financial support from the German Research Foundation (DFG) for the project on "Ethnic Diversity and Labor Market Success" in the DFG-Priority Program "Flexibility in Heterogeneous Labor Markets" is gratefully acknowledged. We would like to thank Silke Anger, Marco Caliendo, Martin Fischer, Regina Flake, Samuel Gosney, Ricarda Schmidl as well as seminar and conference participants in Berlin, Bonn, Catanzaro, Dortmund, London, Pafos, Vancouver and Washington DC for helpful comments and discussions. All remaining errors are our own.
} 


\section{Introduction}

Native-migrant gaps in economic outcomes are documented in many countries. This is per se not very surprising - given that migrants are selected groups (Borjas, 1987), that their human capital may not be entirely transferable (Chiswick, 1978; Borjas, 1985), that their language skills may be insufficient (Dustmann and Fabbri, 2003), and that they may face discrimination (Bertrand and Mullainathan, 2004). However, the extent to which these gaps are persistent across migrant generations is startling. Algan et al. (2010) find intergenerational progress for second generation migrants in France, Germany and the United Kingdom, but the performance deficits in comparison to native peers remain substantial (see also OECD, 2006; Schneeweis, 2011).

This paper focuses on the gap in education outcomes since education is widely perceived as the main channel through which migrant families could economically catch up over generations with the native population. Despite of a growing number of related studies, ${ }^{1}$ the literature has not yet arrived at a unique answer as to whether differences in socioeconomic family background can (entirely) explain the native-migrant gaps in education. On the one hand, a strand of the literature argues that the performance differences are, at least in part, associated with the children's migration background per se through migrant-specific factors such as institutional discrimination, school segregation or language ability (see, e.g., OECD, 2006)—even after controlling for socioeconomic background. On the other hand, a relatively large part of the literature argues that it is predominantly the disadvantage of migrant children in terms of socioeconomic status which leads to these gaps in Germany (e.g., Entorf and Tatsi, 2009; Lüdemann and Schwerdt, 2012). Consequently, only little ethnic inequality remains after controlling for the families' social background. The findings of Luthra (2010) even indicate a migrant advantage over native youths.

Against this background, this paper provides a further assessment of the current understanding of ethnic inequalities in Germany's education system. We explicitly decompose the native-migrant education gap into a part explained by compositional differences in socioeconomic background and an unexplained part, which is likely related to migrant-specific factors. Our analysis is based on a twofold decomposition approach. Next to linear decomposition methods, we use matching techniques to arrive at a picture that is robust to methodological variations. We further add to the literature by examining three different out-

\footnotetext{
${ }^{1}$ The international literature on the educational attainment of second generation migrants is relatively large and growing (e.g., Borjas, 1992; van Ours and Veenman, 2003; Nielsen et al., 2003; Cobb-Clark and Nguyen, 2010; Belzil and Poinas, 2010). There are moreover several studies for Germany documenting a persistent native-migrant gap in education outcomes (e.g., Haisken-DeNew et al., 1997; Gang and Zimmermann, 2000; Riphahn, 2003, 2005).
} 
comes for the same individuals spanning a crucial period in children's educational careers around and after their transition into secondary schooling. These outcomes moreover vary in the degree to which they are influenced by teachers, parents and children. We use recent data that are continuously collected and, for the first time, sample sizes allow for studying this important topic with these data. We are thus able to shed light on a heavily debated question from different angles in terms of methods, outcomes and data.

Our results show first, that second generation migrants differ from their native peers in important characteristics. We observe significant differences in terms of household characteristics and parental background. Second, these differences appear entirely responsible for differences in recommendations given by teachers for and enrollment rates at different secondary school types. Also the gaps in educational attainment at age 17 can be attributed to differences in socioeconomic background. In other words, comparable natives face similar difficulties and show similar education outcomes as migrant children.

The remainder of this paper is organized as follows. Section 2 briefly describes the institutional background of this paper. After describing our data and our sample in Section 3, we outline and discuss our empirical approach in Section 4 and present our results in Section 5. A sensitivity analysis is performed in Section 6 and Section 7 concludes.

\section{Institutional Background}

\subsection{Germany's Secondary Education System}

Important decisions are made relatively early in Germany's education system. One crucial point in time is the transition from primary to secondary schooling. At around the age of 10 years, i.e., after four years of primary education, pupils are tracked into three different types of secondary schooling. ${ }^{2}$

Traditionally, secondary schooling in Germany is divided into the following three types: a) a lower secondary school (Hauptschule), which is designed to prepare pupils for manual professions, $b$ ) an intermediate secondary school (Realschule), which prepares students for administrative and lower white-collar jobs, and c) an upper secondary school (Gymnasium), the school type which prepares for higher education. Only the latter track allows for direct access to universities. All three types are typically public and tuition-free.

The decision of secondary school placement is made jointly by parents and teachers. Primary school teachers recommend a secondary school track, but

\footnotetext{
${ }^{2}$ Note that some variation exists in this regard as education legislation is made by the federal states.
} 
these recommendations are not binding in most federal states.This early tracking system could run the risk of cementing educational careers at an early age. For example, different curricula for the respective school types may leave only little room for later upward mobility.

\subsection{Migrants in Germany}

Germany's migration history after World War II started during the post-war economic boom, when the country focused on the recruitment of low-skilled foreign labor. Many of these guest workers from Southern European countries, who arrived until 1973, settled and were joined by their spouses. The group which is nowadays referred to as second generation migrants mainly consists of the offspring of those migrants. In the late 1980s and early 1990s, Germany experienced massive immigration flows of ethnic Germans from Eastern Europe. Subsequently, Germany also received a relatively large number of humanitarian migrants; and particularly after the enlargement of the European Union (EU) in 2004 and 2007, migration streams from Central and Eastern European countries have been substantial and increasing. ${ }^{3}$

Today's composition of migrants in Germany is therefore dominated by five groups: $a$ ) guest workers and their spouses, $b$ ) their offspring, $c$ ) ethnic Germans from Eastern Europe, $d$ ) recent immigrants from the EU and accession countries, and $e$ ) humanitarian migrants. Turks are by far the largest group of individuals with a migration background, followed by Poles, Russians and Italians. In 2010, 19.3 percent of the German population (or 15.7 million individuals) had a migration background (Statistisches Bundesamt, 2010). Among children aged 5 and below, around one third (34.85 percent) is descended from a migrant family.

Although the group of migrant children represents a large and growing part of the German population, the situation of second generation migrants with respect to educational attainment is alarming. The share among individuals with a migration background who end up enrolling in the lowest secondary schooling track is about twice as large as among natives (Maaz et al., 2010). This may, however, be related to the particular selection process of the parent generation, i.e., mainly guest workers who were actively recruited by German firms until 1973. In contrast to other immigration countries, there had been no positive selection of migrants when compared to the native population. The aim was rather to fill temporary shortages of low-skilled labor, and thus primarily low-skilled workers were recruited.

\footnotetext{
${ }^{3}$ See, e.g., Kahanec and Zimmermann (2009) for a comprehensive analysis of the consequences of east-to-west labor migration for the old and new EU member states.
} 


\section{Data}

The data of this study stem from the German Socio-Economic Panel Study (SOEP). ${ }^{4}$ The SOEP is a representative longitudinal study of private households in Germany. Interviews are conducted in annual waves starting in 1984. As we focus on children in the education system, we take advantage of information collected from 17-year-old first-time respondents. The so-called youth questionnaire was introduced in 2001 and contains retrospective questions about the school career, music education and sport activities. This includes, for example, self-reported information about recommendations for secondary schooling and grade repetition, which are rarely available in other datasets. ${ }^{5}$

Next to the youth questionnaires from 2001 to 2009, we use information on parental and household characteristics from the regular SOEP. These are measured when the children were 10 years old, i.e., when the transition to secondary schooling typically takes place. Our sample is thus restricted to those children whose parents are observed in the SOEP at this time. We furthermore focus on individuals living in West Germany as the share of migrants in East Germany is still relatively low. We discard observations with missing information in important characteristics and we exclude children who attend comprehensive schools from our analysis. It is not possible to distinguish between different tracks at these schools in our data.

Our final sample consists of 770 individuals. Among those are 540 native children and 230 children with migration background. We define children with migration background as children who are either $a$ ) German-born with at least one of their parents being not German-born, or b) not German-born, but migrated to Germany when they were younger than 6 years. ${ }^{6}$

Table 1 displays summary statistics of individual and household characteristics in our sample by migration background. Second generation migrants differ from natives when they are 10 years old. The household income of migrants is on average lower than in native households and there are more children in migrant households. Importantly, the difference with respect to the parents' years of education is substantial as native parents spent on average 1.5 years more in education than migrant parents. Mothers of migrants are significantly less likely to work. Their fathers are also less likely to be employed-and if they are employed, most of them are blue-collar workers. Finally, both immigrant fathers and mothers are on average slightly younger than their native counterparts.

\footnotetext{
${ }^{4}$ See Wagner et al. (2007) for a comprehensive description of this data set.

${ }^{5}$ Ochsen (2011) also analyzes recommendations using SOEP data. Recommendations for secondary schooling are also included in an extension to the German PISA 2000 study, as well as in the PIRLS 2001 study (PISA-E and PIRLS-E).

${ }^{6}$ The mandatory school entrance age is 6 years in Germany.
} 
Table 1 about here

Table 2 shows the distribution of individuals in our sample across Germany's federal states and according to the population size of the respective region of residence. First, we observe significant differences in the shares of migrants and natives in the federal states. Second, migrants are more likely to live in relatively densely populated regions. Therefore, the regional distribution of migrants indicates important differences when compared to natives.

Table 2 about here

The information displayed in Table 3 shows that more than half of the migrant children in our sample have a migration background in one of the former guest worker countries. Roughly one fourth of the children in our sample is of Turkish origin.

\section{Table 3 about here}

To investigate the native-migrant gap at different stages throughout pupils' progression in the German education system, we examine three outcome variables: $a$ ) teacher recommendations received at the end of primary school, $b$ ) actual first enrollment in one of the three secondary school types, and c) track attendance at age 17, i.e., when children answer the SOEP youth questionnaire. If children are not enrolled at the age of 17 years, the latter measure indicates the highest secondary school degree. Throughout this paper, we use the term "education outcomes" for the outcome variables we consider. While this might be correct in an empirical sense, we should at this point acknowledge the distinction between education outcomes and education choices. In our context, at least the first enrollment decision reflects a choice of the child and/or the parents rather than an education outcome in the narrow sense. However, adequately assessing such education choices would require a structural approach which is beyond the scope of this paper. We therefore use the term education outcomes throughout our reduced form analysis, although we are aware of its inaccuracy for describing some of our outcome variables. This should not affect our findings, but it may be relevant for their interpretation.

The education outcomes of migrant and native children are depicted in Table 4. The distribution of recommendations shows important differences between migrant and native children. Whereas more than half of the native children are recommended to attend upper secondary school, this is the case for only about one third of the migrant children. About one in four migrant children are recommended to enter lower secondary school. Only 17 percent of native children receive such a recommendation. It thus appears that a considerable larger share of migrant children receive recommendations for lower 
types of secondary schooling. This picture changes only slightly when looking at which type of secondary school the children actually enroll in. About one third of the migrant children in our sample enroll in each secondary school type, whereas half of the native children enroll in an upper secondary school. The other half of native children distributes evenly across the remaining two types of secondary schools. ${ }^{7}$ When considering the educational attainment around the age of 17 years, we note some upward mobility over time. However, the differences between native and migrant children persist. It is still the case that relatively more native children attain upper secondary schooling, whereas more migrant children attain the lowest secondary schooling track.

\section{Table 4 about here}

The descriptive analysis shows that next to migrant and native pupils' education outcomes, migrant parents' human capital endowment and socioeconomic status differ from average native parents' characteristics. The regional distribution of native and migrant families is also different. Because these characteristics are potentially important determinants of education outcomes, our subsequent analysis decomposes the native-migrant education gap into a part explained by socioeconomic family background and a migrant-specific part.

\section{Empirical Approach}

One important aspect when analyzing and comparing the education outcomes of migrant children with those of their native peers is to adequately take into account that second generation migrants grow up in households which substantially differ from the average native household. This leaves us with a decomposition problem. One part of the native-migrant gap in education outcomes can be attributed to differences in average socioeconomic background characteristics between the two groups. The second part is due to differences in average returns to these characteristics, which are specifically associated with pupils' migration background and may reflect migrant-specific barriers to educational progression (e.g., language skills or discrimination). To isolate these two parts, we employ two different approaches: $a$ ) a linear (OLS) decomposition, and $b$ ) a decomposition using matching techniques. This decomposition strategy is similar to Caliendo and Lee (2012) who decompose differences in the job search behavior between obese and non-obese individuals.

\footnotetext{
${ }^{7}$ There are some observable downward deviations of first secondary school enrollment compared with previous teacher recommendations. However, further analysis (available upon request) shows that this behavior does not systematically differ between native and migrant children.
} 
Linear decomposition methods are widely used in the literature to measure unexplained gaps in mean outcomes between population groups of interest. A common approach is based on the seminal work by Blinder (1973) and Oaxaca (1973). Omitting the details, Elder et al. (2010) show that a seemingly naïve OLS regression including a group indicator variable is an attractive option to obtain a single measure of the unexplained gap. The authors show that under certain conditions, the coefficient on the group indicator variable is a weighted average of the unexplained gaps from the two standard Blinder-Oaxaca approaches. In a first step, we therefore follow this approach to decompose the native-migrant gap in education outcomes. ${ }^{8}$

We additionally employ matching techniques as an alternative decomposition strategy. Although these methods are primarily used in the evaluation literature to estimate treatment effects (see, e.g., Rinne et al., 2011), matching estimators are also employed to measure unexplained gaps (Frölich, 2007; Nopo, 2008; Kiss, 2011). It is important to note that imposing the usual conditional independence assumption is not necessary in this context. Any unobserved variable will contribute to the residual term, i.e., the unexplained part of the gap. More specifically, we use a propensity score matching method of which there are several suggested in the literature (see, e.g., Caliendo and Kopeinig, 2008, for an overview). Based on the characteristics of our data, we apply kernel matching. This nonparametric matching algorithm has advantages in relatively small samples because it uses weighted averages of (nearly) all individuals in the control group to construct the counterfactual outcome.

When comparing linear and matching decompositions, there are distinctive features that justify using both estimators. First, the two approaches place different weights on observations in the population groups of interest (see Angrist and Pischke, 2008, p. 76, for a discussion). Second, the matching decomposition does not specify the regression function as linear. Third, the matching decomposition imposes a common support restriction. In contrast, linear decompositions are based on the assumption that estimations are also valid in regions of the data where there is no support of individual characteristics.

\section{Results}

We consider three different outcome variables. First, we look at the recommendations each child receives when he or she leaves primary school. Second, we investigate the actual transitions to one of the three different secondary schooling types. Finally, we assess the educational attainment when the child answers

\footnotetext{
${ }^{8}$ Empirical applications using linear decomposition methods include Neal and Johnson (1996) who decompose racial wage gaps and Fryer and Levitt (2004) who decompose racial test score gaps.
} 
the youth questionnaire. For each outcome, we analyze two dummy variables: a) an indicator for the upper and intermediate secondary schooling track, and b) an indicator for the upper secondary schooling track. In this way, we respect the ordinal nature of our outcome measures. At the same time, this approach allows for investigating the respective gaps with regard to each schooling level.

\subsection{Linear Decomposition}

Table 5 displays the results of the linear (OLS) decomposition. When only controlling for gender and differences in the regional distribution of migrant and native families, we observe significant and substantial native-migrant gaps in all three outcome variables. Migrant children are about 10 percentage points more likely to receive a recommendation for the lower secondary school track, and they are 20 percentage points less likely to be recommended to the upper secondary school track. These gaps only marginally change when we consider the actual enrollment as outcome variable. When considering the educational attainment at a later stage, the differences slightly decrease, but remain significant. Around the age of 17 years, migrant children are about 7 percentage points more likely to attend the lower secondary school track and roughly 16 percentage points less likely to attain the upper secondary school track. The barrier to be recommended to and to enroll in upper secondary school therefore appears particularly relevant for migrant children. This is an important first result, especially when considering that only this school degree allows a direct university enrollment afterwards.

\section{Table 5 about here}

However, the picture entirely changes once we take family background and household characteristics into account. When including variables such as household income and parents' years of education, the conditional native-migrant gap becomes virtually zero for all three outcomes. The coefficient estimate on the migrant indicator variable is insignificant in all cases. The differences in socioeconomic family background therefore seem to account for the entire gap in education outcomes between migrant children and their native peers. In other words, we observe no particular barrier for migrant children to be recommended to and be placed into upper secondary school once background characteristics are taken into account. 


\subsection{Matching Decomposition}

Table 6 presents the decomposition results based on propensity score matching. As stated above, we obtain these results by kernel matching. ${ }^{9}$ The matching quality is satisfactory. The overlap between the groups of migrant children and native children is sufficient in our sample and, hence, we do not drop any observations due to the common support restriction. ${ }^{10}$ After matching, mean standardized differences are substantially reduced, any significant differences in the means of the covariates disappear, and the pseudo- $R^{2}$ is low. ${ }^{11}$ This indicates that no systematic differences between the two groups of migrant and native children remain.

\section{Table 6 about here}

The results of the matching decomposition basically mirror the results of the linear decomposition. The significant native-migrant differences in the three outcome variables that exist before matching disappear after matching and become insignificant. This again shows that differences in socioeconomic family background entirely explain the observed gaps between migrant and native children. However, although the estimates lack statistical significance, the matching decomposition indicates that some economic significance of the unexplained gap remains. Controlling for socioeconomic family background, migrants are about 6 percentage points ( 4 percentage points) less likely to be recommended for (to enroll in) the upper secondary school track. These estimates are about three times larger than in the linear decomposition. However, with respect to our third outcome which is measured at a later stage of secondary education, there is no evidence of any unexplained part of the gap. The estimate is virtually zero. These findings may tentatively indicate that moving along secondary schooling, there is some room for migrant children to use second chances and to improve their relative position with respect to native children over time.

\section{Sensitivity Analysis}

We assess the robustness of our main results in several dimensions. First, we include a measure of cognitive ability in our analysis. Second, we split our sample according to socioeconomic family background. In these two dimensions,

\footnotetext{
${ }^{9}$ The matching algorithm is implemented using the PSMATCH2 Stata ado-package by Leuven and Sianesi (2003). Throughout this paper, the decomposition results using kernel matching are based on a bandwidth parameter of 0.06 . Results remain virtually the same with bandwidth parameters of 0.02 and 0.2 .

${ }^{10}$ See Figure A1 (Appendix) for a visual impression of the propensity score distributions.

${ }^{11}$ See Table A1 (Appendix) for a summary of the matching quality.
} 
we only report the results of matching decompositions as linear decompositions lead to similar results. Finally, we briefly summarize the results of additional robustness checks.

\subsection{Ability}

One potentially important, but so far omitted factor is the children's cognitive ability. It might be of particular importance in our context since pupils are supposed to be tracked according to their ability. A priori and conditional on socioeconomic background, there seems to be no obvious reason to expect differences in the ability distributions of migrant and native children. It is, however, possible that parental production functions of immigrant parents systematically deviate from those of native parents or that there is variation in some unobserved characteristics between migrant and native families. Conditional on cognitive ability, migrant and native pupils might also be differently affected by or able to cope with a disadvantaged family background. We therefore include a measure of cognitive skills in this part of our analysis.

Similar to our main decomposition exercise, we decompose the native-migrant gap into a part explained by average background characteristics as well as cognitive skills, and into an unexplained part which possibly reflects migrant-specific factors. We use a measure of cognitive skills that is available for a subgroup of individuals in our sample. It is part of the SOEP's youth questionnaire since 2006. ${ }^{12}$ This ability measure includes three dimensions of cognitive skills testing verbal, numerical and figural potentials. Importantly, it is argued that fluid rather than crystallized intelligence is captured (Solga et al., 2005). The measure should thus reflect inherent abilities which are stable over time and are not influenced by education, experiences and the course of life. ${ }^{13}$ Given that this assumption holds, we can use this measure even though it is elicited only around the age of 17 years in our data.

\section{Table 7 about here}

Table 7 displays the results of the matching decomposition when we include this ability measure. Information on cognitive skills is available for 449 individuals. Among those are 138 children with a migration background. We exclude 18 observations due to the common support restriction. The results for the unmatched sample are very similar to our full sample results, both with respect to magnitude and statistical significance. We find negative differences for every outcome between the native and migrant group. However, results after

\footnotetext{
${ }^{12}$ See Solga et al. (2005) and Schupp and Herrmann (2009) for a general description. Studies using this measure include Uhlig et al. (2009) and Protsch and Dieckhoff (2011).

${ }^{13}$ See Cattell (1987) for a discussion of the distinction between fluid and crystallized intelligence.
} 
matching are slightly different than in the full sample. The native-migrant gaps remain insignificant, but they turn positive for all but one outcome variable in the matched sample. These positive differences are moreover in some cases quite substantial as they exceed 10 percentage points for two of our outcome variables. Given the same socioeconomic family background and the same cognitive ability, migrant children appear less likely to be recommended for the lowest secondary school track than native children. We find a similar result for the latest enrollment at this type of secondary school. Importantly, these changes compared to our main results are not due to the reduced sample, but due to the inclusion of the ability measure. ${ }^{14}$

These tentative findings seem to be roughly in line with Luthra (2010). Similar to her results, we find at least a weak indication of a possible migrant advantage over native children when we additionally include a measure of cognitive ability. This could potentially point to migrant-specific factors actually working in a different direction than expected. For example, there could be positive discrimination in favor of migrant children-at least once they share the same cognitive skills and background characteristics as their native peers. Alternatively, migrant children with similar inherent ability may be better able to cope with a disadvantaged background than native children.

\subsection{Socioeconomic Status}

The main argument to split the sample according to socioeconomic family background is that migrant families with low socioeconomic status are overrepresented in the full sample. To see whether effects are heterogenous with respect to family background, we use net household income as an approximation of socioeconomic status and split the full sample at the median income of migrant families. ${ }^{15}$

Table 8 displays the matching decomposition results for the low income sample. With 261 observations, its sample size is approximately one third of the full sample. Among the observations are 116 migrant children, from which 2 observations lack comparable native children. The native-migrant education gaps before matching are negative, but not as substantial as in the full sample. Moreover, most differences lack statistical significance-which could be due to the smaller sample size. All differences turn positive after matching, but they are not statistically different from zero. Aside from the small sample size, this seems to indicate that native children from families with low socioeconomic background face similar difficulties in the education system as migrant children

\footnotetext{
${ }^{14}$ Results for the reduced sample without including the ability measure are available upon request.

${ }^{15}$ The median net household income of migrant families is $€ 2744.82$ in the full sample.
} 
with similar background. Moreover, there are indications that unexplained gaps between these two groups do not exist even before matching.

Tables 8 and 9 about here

Table 9 displays results of the matching decomposition for the high income sample. This sample comprises 502 observations, of which 114 children are from migrant families. 10 of these migrant children lack comparable natives and are thus excluded. The results in this sample are similar to the full sample results. Before matching, there are significant native-migrant education gaps in terms of almost all outcomes. These differences are comparable in magnitude to the full sample results - if at all, they are slightly less pronounced. After matching, the differences decrease and some even turn slightly positive, but the gaps do not exhibit statistical significance anymore.

The results for these two samples therefore underline the importance of controlling for socioeconomic background characteristics. Whereas native and migrant children from households in the lower part of the income distribution appear to differ not much in terms of education outcomes (even without controlling for additional characteristics, i.e., before matching), children in the upper part do substantially differ in this regard. The native-migrant education gaps only disappear for those children once we carefully control for differences in socioeconomic background characteristics.

\subsection{Additional Robustness Checks}

We perform four additional sensitivity analyses concerning the composition of our sample (results not reported here). First, we restrict the sample to second generation migrants in a more narrow sense, i.e., children with two immigrant parents, thus excluding children with one migrant and one native parent. Second, we only consider children who attended pre-school education. In our sample, migrants are about 8 percentage points less likely to attend preschool education than natives-and almost every native child (about 97 percent) attends pre-school education. Third, we assess the sensitivity of our results concerning different legislations with respect to teachers' recommendations. In some federal states-namely Schleswig-Holstein, Hamburg, Lower Saxony, North-Rhine Westphalia, Hesse, Rhineland-Palatinate, Saarland and Berlinrecommendations are not necessarily binding. We therefore only consider families living in federal states with non-binding recommendations. These three robustness checks yield similar results to those obtained using the full sample.

Fourth, we are concerned about the migrant children's diverse ethnic backgrounds, i.e., the countries their parents originally came from. Migrant-specific factors might be more or less prevalent for different ethnic groups due to, e.g., 
cultural distance to Germany. Unfortunately, the number of observations in our data is too low to perform the decomposition analysis on each ethnic group separately. We therefore conduct our main analysis solely considering migrant children with a guest worker background. This group of second generation migrants is the largest in our sample and also the one with the least favorable family background. Qualitatively, the results are similar to our main results. After matching, however, we find that guest worker migrant children are still significantly less likely to receive recommendations for and to enroll at the upper secondary school. Both gaps amount to 13 percentage points. These results suggest that for this group, migrant-specific factors seem to play a role at earlier stages in the education system. However, in line with our main results, the unexplained part of the gap disappears when these children progress in the education system, i.e., when considering track attendance at the age of 17 .

\section{Conclusions}

Education is widely perceived as the main channel through which migrant families could economically catch up with natives. Although there is some intergenerational progress in education outcomes for second generation migrants, the performance deficits in comparison to native peers remain substantial. This paper therefore investigates to what extent the native-migrant education gap in Germany is due to compositional differences in parental background and household characteristics between these two groups, and to what extent it is associated with migrant-specific or other factors. In other words, if migrant and native children shared the same socioeconomic background, would we still observe differences in education outcomes?

To answer this question, we apply two different decomposition strategies: linear decompositions as well as decompositions based on matching techniques. Moreover, we examine the issue with respect to three outcomes related to secondary school placement. In particular, we study whether migrant and native children receive different teacher recommendations by the end of primary school, whether they actually enroll in different school types and whether there are differences in educational enrollment at age 17. Our results suggest that, conditional on socioeconomic background, migrant pupils are equally likely to receive recommendations for or to enroll at any secondary school type. Also the gap in education outcomes at age 17 appears to be explained entirely by differences in socioeconomic family background. Hence, there is no indication that a migration background per se hinders the educational progression of second generation migrants (in recent years). Our findings thus point at more general inequalities in the transition to secondary schooling rather than at a migrant-specific problem. 
There are some characteristics of Germany's education system that appear related to our findings (see, e.g., Crul and Vermeulen, 2003). For example, children enter school only at the age of 6 years, and thus a very important stage in the children's development process has already passed. Moreover, most children attend school on a half-day basis and face-to-face contact hours with teachers are below average. Germany also tracks relatively early by international standards. Children from families with a disadvantaged socioeconomic background are thus given little time to pull themselves out of their disadvantaged starting position. Finally, Germany is well below average with respect to the amount of supplementary help and support available to children inside and outside school. Although all these factors may create migrant-specific barriers to educational progression, they seem to create similar barriers for natives from a disadvantaged family background. Future research may analyze the channels through which this "socioeconomic" gap exactly emerges. It may also be interesting to investigate whether and how this gap affects labor market outcomes. ${ }^{16}$

\section{References}

Algan, Y., Dustmann, C., Glitz, A., Manning, A., 2010. The Economic Situation of Firstand Second-Generation Immigrants in France, Germany, and the United Kingdom. The Economic Journal 120 (542), 4-30.

Angrist, J. D., Pischke, J.-S., 2008. Mostly Harmless Econometrics: An Empiricist's Companion. Princeton University Press, New Jersey.

Belzil, C., Poinas, F., 2010. Education and Early Career Outcomes of Second-Generation Immigrants in France. Labour Economics 17 (1), 101-110.

Bertrand, M., Mullainathan, S., 2004. Are Emily and Greg more Employable than Lakisha and Jamal? A Field Experiment on Labor Market Discrimination. American Economic Review 94 (4), 991-1013.

Blinder, A. S., 1973. Wage Discrimination: Reduced Form and Structural Estimates. Journal of Human Resources 8 (4), 436-455.

Borjas, G., 1985. Assimilation, Changes in Cohort Quality, and the Earnings of Immigrants. Journal of Labor Economics 3 (4), 463-489.

Borjas, G., 1987. Self-Selection and the Earnings of Immigrants. American Economic Review 77 (4), 531-553.

\footnotetext{
${ }^{16}$ See, e.g., Tasiran and Tezic (2007) for evidence from Sweden.
} 
Borjas, G. J., 1992. Ethnic Capital and Intergenerational Mobility. Quarterly Journal of Economics 107 (1), 123-150.

Caliendo, M., Kopeinig, S., 2008. Some Practical Guidance for the Implementation of Propensity Score Matching. Journal of Economic Surveys 22 (1), 31-72.

Caliendo, M., Lee, W.-S., 2012. Fat Chance! Obesity and the Transition from Unemployment to Employment. Economics and Human Biology (forthcoming).

Cattell, R. B., 1987. Intelligence: Its Structure, Growth and Action. Elsevier Science Publishers, New York.

Chiswick, B. R., 1978. The Effect of Americanization on the Earnings of Foreign-born Men. Journal of Political Economy 86 (5), 897-921.

Cobb-Clark, D. A., Nguyen, H. T., 2010. Immigration Background and the Intergenerational Correlation in Education. IZA Discussion Paper 4985, Institute for the Study of Labor (IZA), Bonn.

Crul, M., Vermeulen, H., 2003. The Second Generation in Europe. International Migration Review 37 (4), 965-986.

Dustmann, C., Fabbri, F., 2003. Language Proficiency and Labour Market Performance of Immigrants in the UK. The Economic Journal 113 (489), 695-717.

Elder, T., Goddeeris, J. H., Haider, S. J., 2010. Unexplained Gaps and Oaxaca-Blinder Decompositions. Labour Economics 17 (1), 284-290.

Entorf, H., Tatsi, E., 2009. Migrants at School: Educational Inequality and Social Interaction in the UK and Germany. IZA Discussion Paper 4175, Institute for the Study of Labor (IZA), Bonn.

Frölich, M., 2007. Propensity Score Matching without Conditional Independence Assumption with an Application to the Gender Wage Gap in the United Kingdom. Econometrics Journal 10 (2), 359-407.

Fryer, R. G., Levitt, S. D., 2004. Understanding the Black-White Test Score Gap in the First Two Years of School. The Review of Economics and Statistics 86 (2), 447-464.

Gang, I. N., Zimmermann, K. F., 2000. Is Child like Parent? Educational Attainment and Ethnic Origin. Journal of Human Resources 35 (3), 550 -569.

Haisken-DeNew, J., Büchel, F., Wagner, G. G., 1997. Assimilation and Other Determinants of School Attainment in Germany: Do Immigrant Children Perform as Well as Germans? Vierteljahrshefte zur Wirtschaftsforschung 66 (1), 169-179.

Kahanec, M., Zimmermann, K. F. (Eds.), 2009. EU Labor Markets After Post-Enlargement Migration. Springer, Berlin et al.

Kiss, D., 2011. Are Immigrants and Girls Graded Worse? Results of a Matching Approach. Education Economics, DOI:10.1080/09645292.2011.585019.

Lüdemann, E., Schwerdt, G., 2012. Migration Background and Educational Tracking: Is there a Double Disadvantage for Second-Generation Immigrants? Journal of Population Economics, DOI: 10.1007/s00148-012-0414-z. 
Leuven, E., Sianesi, B., 2003. PSMATCH2: Stata module to perform full Mahalanobis and propensity score matching, common support graphing, and covariate imbalance testing. Statistical Software Components, Boston College Department of Economics, available at http://ideas.repec.org/c/boc/bocode/s432001.html.

Luthra, R. R., 2010. Assimilation in a New Context: Educational Attainment of the Immigrant Second Generation in Germany. ISER Working Paper 2010-21, Institute for Social and Economic Research (ISER), Essex.

Maaz, K., Baumert, J., Gresch, C., McElvany, N., 2010. Der Übergang von der Grundschule in die weiterführende Schule: Leistungsgerechtigkeit und regionale, soziale und ethnisch-kulturelle Disparitäten. Bildungsforschung Band 34. Bundesministerium für Bildung und Forschung (BMBF), Bonn and Berlin.

Neal, D. A., Johnson, W. R., 1996. The Role of Premarket Factors in Black-White Wage Differences. Journal of Political Economy 104 (5), 869-895.

Nielsen, H. S., Rosholm, M., Smith, N., Husted, L., 2003. The School-to-Work Transition of 2nd Generation Immigrants in Denmark. Journal of Population Economics, 2003, vol. 16, issue 4, pages 16 (4), 755-786.

Nopo, H., 2008. Matching as a Tool to Decompose Wage Gaps. Review of Economics and Statistics 90 (2), 290-299.

Oaxaca, R., 1973. Male-Female Wage Differentials in Urban Labor Markets. International Economic Review 14 (3), 693-709.

Ochsen, C., 2011. Recommendation, Class Repeating, and Children's Ability: German School Tracking Experiences. Applied Economics 43 (27), 4127-4133.

OECD, 2006. Where Immigrant Students Succeed: A Comparative Review of Performance and Engagement in PISA 2003. Organization for Economic Cooperation and Development (OECD), Paris.

Protsch, P., Dieckhoff, M., 2011. What Matters in the Transition from School to Vocational Training in Germany. European Societies 13 (1), 69-91.

Rinne, U., Schneider, M., Uhlendorff, A., 2011. Do the Skilled and Prime-Aged Unemployed Benefit More from Training? Effect Heterogeneity of Public Training Programs in Germany. Applied Economics 43 (25), 3465-3494.

Riphahn, R. T., 2003. Cohort Effects in the Educational Attainment of Second Generation Immigrants in Germany: An Analysis of Census Data. Journal of Population Economics 16(4), 711-737.

Riphahn, R. T., 2005. Are there Diverging Time Trends in the Educational Attainment of Nationals and Second Generation Immigrants? Journal of Economics and Statistics 225 (3), 325-346.

Schneeweis, N., 2011. Educational Institutions and the Integration of Migrants. Journal of Population Economics 24 (4), 1281-1308.

Schupp, J., Herrmann, S., 2009. Kognitionspotenziale Jugendlicher: Ergänzung zum Jugendfragebogen der Längsschnittstudie Sozio-oekonomisches Panel (SOEP). Data Documentation 43, German Institute for Economic Research (DIW Berlin), Berlin. 
Solga, H., Stern, E., von Rosenbladt, B., Schupp, J., Wagner, G. G., 2005. The Measurement and Importance of General Reasoning Potentials in Schools and Labor Markets: Pre-Test Report. Research Notes 10, German Institute for Economic Research (DIW Berlin), Berlin.

Statistisches Bundesamt, 2010. Bevölkerung und Erwerbstätigkeit: Bevölkerung mit Migrationshintergrund - Ergebnisse des Mikrozensus 2010. Fachserie 1, Reihe 2.2.

Tasiran, A., Tezic, K., 2007. Early Labor Market Experiences of Second-Generation Immigrants in Sweden. Applied Economics 39 (7), 809-824.

Uhlig, J., Solga, H., Schupp, J., 2009. Ungleiche Bildungschancen: Welche Rolle spielen Underachievement und Persönlichkeitsstruktur dabei? Discussion Paper SP I 2009503, Social Science Research Center Berlin (WZB), Berlin.

van Ours, J. C., Veenman, J., 2003. The Educational Attainment of Second-Generation Immigrants in the Netherlands. Journal of Population Economics 16 (4), 739-753.

Wagner, G. G., Frick, J. R., Schupp, J., 2007. The German Socio-Economic Panel Study (SOEP) - Scope, Evolution and Enhancements. Schmollers Jahrbuch 127 (1), 139169. 
Table 1: Descriptive Statistics I (Individual and Household Characteristics)

\begin{tabular}{lccc}
\hline & Natives & Migrants & t-stat \\
\hline Male & $0.519(0.500)$ & $0.413(0.493)$ & $2.689^{* * * *}$ \\
Logarithm household income & $8.120(0.405)$ & $7.958(0.373)$ & $5.214^{* * *}$ \\
Number of children in household & $2.213(0.954)$ & $2.509(1.337)$ & $-3.470^{* * *}$ \\
Single parent household & $0.067(0.250)$ & $0.061(0.240)$ & 0.298 \\
Parents' years of education & $12.416(2.387)$ & $10.943(2.298)$ & $7.924^{* * * *}$ \\
\hline Mother working & $0.643(0.480)$ & $0.422(0.495)$ & $5.792^{* * *}$ \\
Father not working & $0.033(0.180)$ & $0.130(0.338)$ & $-5.183^{* * *}$ \\
Father blue-collar worker & $0.311(0.463)$ & $0.565(0.495)$ & $-6.814^{* * * *}$ \\
Father self-employed & $0.130(0.336)$ & $0.074(0.262)$ & $2.240^{* * *}$ \\
Father employee & $0.424(0.495)$ & $0.217(0.413)$ & $5.563^{* * *}$ \\
Father civil servant & $0.102(0.303)$ & $0.013(0.114)$ & $4.320^{* * * *}$ \\
\hline Mother's age & $38.307(4.491)$ & $36.317(5.375)$ & $5.296^{* * * *}$ \\
Father's age & $41.044(5.435)$ & $39.183(6.494)$ & $4.097^{* * * *}$ \\
\hline \# Observations & 540 & 230 & \\
\hline
\end{tabular}

Source: SOEP, own calculations.

Notes: Natives: German-born and German citizen, and parents German-born; migrants: German-born, but not German citizen or at least one parent not German-born, or not German-born, but migrated to Germany when younger than 6 years. Standard deviations in parentheses.

*** significant at $1 \%$; ** significant at $5 \%$; * significant at $10 \%$.

Table 2: Descriptive Statistics II (Regional Characteristics)

\begin{tabular}{lccc}
\hline & Natives & Migrants & t-stat \\
\hline Bavaria & $0.176(0.381)$ & $0.109(0.312)$ & $2.360^{* *}$ \\
Schleswig-Holstein & $0.065(0.246)$ & $0.022(0.146)$ & $2.472^{* *}$ \\
Hamburg & $0.007(0.086)$ & $0.017(0.131)$ & -1.250 \\
Lower Saxony & $0.106(0.308)$ & $0.148(0.356)$ & $-1.664^{*}$ \\
North Rhine-Westphalia & $0.270(0.445)$ & $0.270(0.455)$ & 0.023 \\
Hesse & $0.078(0.268)$ & $0.039(0.194)$ & $1.976^{* *}$ \\
Rhineland-Palatinate, Saarland & $0.102(0.303)$ & $0.117(0.323)$ & -0.639 \\
Baden-Wuerttemberg & $0.178(0.383)$ & $0.243(0.430)$ & $-2.100^{* *}$ \\
Berlin & $0.019(0.135)$ & $0.035(0.184)$ & -1.367 \\
\hline Region of residence population $<20 \mathrm{k}$ & $0.515(0.500)$ & $0.361(0.481)$ & $3.952^{* * *}$ \\
Region of residence population 20k-100k & $0.257(0.438)$ & $0.278(0.449)$ & -0.601 \\
Region of residence population 100k-500k & $0.135(0.342)$ & $0.222(0.416)$ & $-3.004 * * *$ \\
Region of residence population $>500 \mathrm{k}$ & $0.093(0.290)$ & $0.139(0.347)$ & $-1.918^{*}$ \\
\hline \# Observations & 540 & 230 & \\
\hline Source: SOEP, own calculations. & & \\
Notes: Natives: German-born and German citizen, and parents German-born; migrants: German-born, but \\
not German citizen or at least one parent not German-born, or not German-born, but migrated to Germany \\
when younger than 6years. No individual in our sample lives in Bremen. Standard deviations in parentheses. \\
*** significant at 1\%; ** significant at 5\%; * significant at 10\%.
\end{tabular}


Table 3: Descriptive Statistics III (Migration Background)

\begin{tabular}{lr}
\hline Country of Origin (Parents) & Percent \\
\hline Turkey & 27.39 \\
Italy & 10.87 \\
Former Yugoslavia & 7.39 \\
Greece & 5.22 \\
Spain & 3.48 \\
Russia/Former Soviet Republics & 13.48 \\
Poland & 10.43 \\
Other Countries & 21.74 \\
\hline \# Observations & 230 \\
\hline
\end{tabular}

Source: SOEP, own calculations.

Note: Migrants: German-born, but not German citizen or at least one parent not German-born, or not German-born, but migrated to Germany when younger than 6 years.

Table 4: Descriptive Statistics IV (Education Outcomes)

\begin{tabular}{|c|c|c|c|}
\hline & Natives & Migrants & t-stat \\
\hline \multicolumn{4}{|l|}{ Recommendation } \\
\hline Lower Secondary School & $0.170(0.376)$ & $0.257(0.438)$ & $-2.766 * * *$ \\
\hline Intermediate Secondary School & $0.304(0.460)$ & $0.409(0.493)$ & $-2.836 * * *$ \\
\hline Upper Secondary School & $0.526(0.500)$ & $0.335(0.473)$ & $4.935 * * *$ \\
\hline \multicolumn{4}{|l|}{ First Enrollment } \\
\hline Lower Secondary School & $0.239(0.427)$ & $0.339(0.474)$ & $-2.883 * * *$ \\
\hline Intermediate Secondary School & $0.256(0.437)$ & $0.339(0.474)$ & $-2.368 * *$ \\
\hline Upper Secondary School & $0.506(0.500)$ & $0.322(0.468)$ & $4.754 * * *$ \\
\hline \multicolumn{4}{|l|}{ Latest Enrollment } \\
\hline Lower Secondary School & $0.072(0.259)$ & $0.143(0.351)$ & $-3.124 * * *$ \\
\hline Intermediate Secondary School & $0.367(0.482)$ & $0.447(0.498)$ & $-2.112 * *$ \\
\hline Upper Secondary School & $0.561(0.497)$ & $0.409(0.493)$ & $3.907 * * *$ \\
\hline \# Observations & 540 & 230 & \\
\hline \multicolumn{4}{|c|}{$\begin{array}{l}\text { Source: SOEP, own calculations. } \\
\text { Note: Natives: German-born and German citizen, and parents German-born; migrants: German-born, but not } \\
\text { German citizen or at least one parent not German-born, or not German-born, but migrated to Germany when } \\
\text { younger than } 6 \text { years. Standard deviations in parentheses. } \\
* * * * \text { significant at } 1 \% ; * * \text { significant at } 5 \% ; * \text { significant at } 10 \% \text {. }\end{array}$} \\
\hline
\end{tabular}


Table 5: Linear Decomposition (OLS, Full Sample)

\begin{tabular}{|c|c|c|c|c|}
\hline & (1) & (2) & (3) & (4) \\
\hline Recommendation & \multicolumn{2}{|c|}{ Upper/Int. vs. Lower Track } & \multicolumn{2}{|c|}{ Upper vs. Int./Lower Track } \\
\hline Migration Background & $\begin{array}{c}-0.101^{* * *} \\
(0.03)\end{array}$ & $\begin{array}{c}-0.006 \\
(0.03)\end{array}$ & $\begin{array}{c}-0.199^{* * *} \\
(0.04)\end{array}$ & $\begin{array}{c}-0.021 \\
(0.04)\end{array}$ \\
\hline Regional Characteristics & Yes & Yes & Yes & Yes \\
\hline Household Characteristics & No & Yes & No & Yes \\
\hline Parental Characteristics & No & Yes & No & Yes \\
\hline$N$ & 770 & 770 & 770 & 770 \\
\hline$R^{2}$ & 0.058 & 0.137 & 0.077 & 0.248 \\
\hline AIC & 744.9 & 701.5 & 1081.0 & 947.0 \\
\hline BIC & 809.9 & 822.3 & 1146.0 & 1067.8 \\
\hline First Enrollment & \multicolumn{2}{|c|}{ Upper/Int. vs. Lower Track } & \multicolumn{2}{|c|}{ Upper vs. Int./Lower Track } \\
\hline Migration Background & $\begin{array}{c}-0.112^{* * *} \\
(0.04)\end{array}$ & $\begin{array}{l}0.020 \\
(0.04)\end{array}$ & $\begin{array}{c}-0.189^{* * *} \\
(0.04)\end{array}$ & $\begin{array}{c}-0.008 \\
(0.04)\end{array}$ \\
\hline Regional Characteristics & Yes & Yes & Yes & Yes \\
\hline Household Characteristics & No & Yes & No & Yes \\
\hline Parental Characteristics & No & Yes & No & Yes \\
\hline$N$ & 770 & 770 & 770 & 770 \\
\hline$R^{2}$ & 0.138 & 0.259 & 0.098 & 0.296 \\
\hline AIC & 846.6 & 753.3 & 1058.9 & 891.9 \\
\hline$B I C$ & 911.6 & 874.1 & 1124.0 & 1012.7 \\
\hline Latest Enrollment & \multicolumn{2}{|c|}{ Upper/Int. vs. Lower Track } & \multicolumn{2}{|c|}{ Upper vs. Int./Lower Track } \\
\hline Migration Background & $\begin{array}{c}-0.071^{* *} \\
(0.03)\end{array}$ & $\begin{array}{l}0.015 \\
(0.03)\end{array}$ & $\begin{array}{c}-0.161^{* * *} \\
(0.04)\end{array}$ & $\begin{array}{l}0.024 \\
(0.04)\end{array}$ \\
\hline Regional Characteristics & Yes & Yes & Yes & Yes \\
\hline Household Characteristics & No & Yes & No & Yes \\
\hline Parental Characteristics & No & Yes & No & Yes \\
\hline$N$ & 770 & 770 & 770 & 770 \\
\hline$R^{2}$ & 0.030 & 0.134 & 0.075 & 0.276 \\
\hline AIC & 289.2 & 226.5 & 1085.0 & 920.4 \\
\hline BIC & 354.3 & 347.3 & 1150.0 & 1041.2 \\
\hline
\end{tabular}

Source: SOEP, own calculations.

Note: Clustered standard errors by household in parentheses. Regional characteristics: federal states, population density. Household characteristics: household income, number of children, single parent household. Parental characteristics: parents' years of education, age, employment status. Other control variable: gender. *** significant at $1 \%$; ** significant at $5 \%$; * significant at $10 \%$. 
Table 6: Matching Decomposition (Kernel Matching, Full Sample)

\begin{tabular}{lccccc}
\hline \multicolumn{1}{c}{ Outcome } & Sample & Migrants & Natives & Difference & SE \\
\hline Recommendation & Unmatched & 0.743 & 0.830 & $-0.086^{* * *}$ & 0.031 \\
(Upper/Intermediate vs. Lower Track) & Matched & 0.743 & 0.736 & 0.007 & 0.050 \\
Recommendation & Unmatched & 0.335 & 0.526 & $-0.191^{* * *}$ & 0.039 \\
(Upper vs. Intermediate/Lower Track) & Matched & 0.335 & 0.398 & -0.064 & 0.048 \\
\hline First Enrollment & Unmatched & 0.661 & 0.761 & $-0.100^{* * *}$ & 0.035 \\
(Upper/Intermediate vs. Lower Track) & Matched & 0.661 & 0.673 & -0.012 & 0.051 \\
First Enrollment & Unmatched & 0.322 & 0.506 & $-0.184^{* * *}$ & 0.039 \\
(Upper vs. Intermediate/Lower Track) & Matched & 0.322 & 0.359 & -0.038 & 0.048 \\
\hline Latest Enrollment & Unmatched & 0.857 & 0.928 & $-0.071^{* * *}$ & 0.023 \\
(Upper/Intermediate vs. Lower Track) & Matched & 0.857 & 0.839 & 0.017 & 0.047 \\
Latest Enrollment & Unmatched & 0.409 & 0.561 & $-0.152^{* * *}$ & 0.039 \\
(Upper vs. Intermediate/Lower Track) & Matched & 0.409 & 0.418 & -0.009 & 0.053 \\
\hline \# Observations Total & & & 770 & & \\
\# Observations On Support & & & 770 & & \\
\hline
\end{tabular}

Source: SOEP, own calculations.

Note: Standard errors are bootstrapped (200 replications).

*** significant at $1 \%$; ** significant at $5 \%$; * significant at $10 \%$.

Table 7: Matching Decomposition (Kernel Matching, Ability Sample)

\begin{tabular}{lccccc}
\hline \multicolumn{1}{c}{ Outcome } & Sample & Migrants & Natives & Difference & SE \\
\hline Recommendation & Unmatched & 0.739 & 0.830 & $-0.090^{* *}$ & 0.040 \\
(Upper/Intermediate vs. Lower Track) & Matched & 0.750 & 0.646 & 0.104 & 0.086 \\
Recommendation & Unmatched & 0.341 & 0.524 & $-0.184^{* * *}$ & 0.050 \\
(Upper vs. Intermediate/Lower Track) & Matched & 0.367 & 0.314 & 0.053 & 0.078 \\
\hline First Enrollment & Unmatched & 0.645 & 0.752 & $-0.107^{* *}$ & 0.046 \\
(Upper/Intermediate vs. Lower Track) & Matched & 0.692 & 0.676 & 0.043 & 0.079 \\
First Enrollment & Unmatched & 0.290 & 0.492 & $-0.202^{* * *}$ & 0.050 \\
(Upper vs. Intermediate/Lower Track) & Matched & 0.317 & 0.326 & -0.002 & 0.066 \\
\hline Latest Enrollment & Unmatched & 0.862 & 0.929 & $-0.067^{* *}$ & 0.029 \\
(Upper/Intermediate vs. Lower Track) & Matched & 0.883 & 0.791 & 0.110 & 0.079 \\
Latest Enrollment & Unmatched & 0.384 & 0.537 & $-0.153^{* * *}$ & 0.051 \\
(Upper vs. Intermediate/Lower Track) & Matched & 0.408 & 0.335 & 0.083 & 0.074 \\
\hline \# Observations Total & & & 449 & & \\
\# Observations On Support & & & 431 & & \\
\hline
\end{tabular}

Source: SOEP, own calculations.

Note: Besides the usual control variables, we additionally control for cognitive abilities, which are measured in the SOEP youth questionnaire since 2006. See main text for further details. Standard errors are bootstrapped (200 replications).

*** significant at $1 \% ; * *$ significant at $5 \% ; *$ significant at $10 \%$. 
Table 8: Matching Decomposition (Kernel Matching, Low Income Sample)

\begin{tabular}{|c|c|c|c|c|c|}
\hline Outcome & Sample & Migrants & Natives & Difference & SE \\
\hline Recommendation & Unmatched & 0.681 & 0.731 & -0.050 & 0.057 \\
\hline (Upper/Intermediate vs. Lower Track) & Matched & 0.684 & 0.584 & 0.100 & 0.102 \\
\hline Recommendation & Unmatched & 0.250 & 0.366 & $-0.116^{* *}$ & 0.058 \\
\hline (Upper vs. Intermediate/Lower Track) & Matched & 0.246 & 0.243 & 0.003 & 0.081 \\
\hline First Enrollment & Unmatched & 0.578 & 0.634 & -0.057 & 0.061 \\
\hline (Upper/Intermediate vs. Lower Track) & Matched & 0.588 & 0.577 & 0.011 & 0.098 \\
\hline First Enrollment & Unmatched & 0.259 & 0.352 & -0.093 & 0.058 \\
\hline (Upper vs. Intermediate/Lower Track) & Matched & 0.263 & 0.238 & 0.025 & 0.081 \\
\hline Latest Enrollment & Unmatched & 0.819 & 0.855 & -0.036 & 0.046 \\
\hline (Upper/Intermediate vs. Lower Track) & Matched & 0.816 & 0.798 & 0.017 & 0.089 \\
\hline Latest Enrollment & Unmatched & 0.319 & 0.448 & $-0.129^{* *}$ & 0.060 \\
\hline (Upper vs. Intermediate/Lower Track) & Matched & 0.316 & 0.295 & 0.021 & 0.086 \\
\hline \# Observations Total & & & 261 & & \\
\hline \# Observations On Support & & & 259 & & \\
\hline
\end{tabular}

Table 9: Matching Decomposition (Kernel Matching, High Income Sample)

\begin{tabular}{|c|c|c|c|c|c|}
\hline Outcome & Sample & Migrants & Natives & Difference & SE \\
\hline Recommendation & Unmatched & 0.807 & 0.863 & -0.056 & 0.038 \\
\hline (Upper/Intermediate vs. Lower Track) & Matched & 0.808 & 0.790 & 0.018 & 0.066 \\
\hline Recommendation & Unmatched & 0.421 & 0.585 & $-0.164^{* * *}$ & 0.053 \\
\hline (Upper vs. Intermediate/Lower Track) & Matched & 0.433 & 0.493 & -0.060 & 0.081 \\
\hline First Enrollment & Unmatched & 0.746 & 0.807 & -0.061 & 0.043 \\
\hline (Upper/Intermediate vs. Lower Track) & Matched & 0.750 & 0.722 & 0.028 & 0.068 \\
\hline First Enrollment & Unmatched & 0.386 & 0.562 & $-0.176^{* * *}$ & 0.053 \\
\hline (Upper vs. Intermediate/Lower Track) & Matched & 0.394 & 0.453 & -0.059 & 0.076 \\
\hline Latest Enrollment & Unmatched & 0.895 & 0.954 & $-0.059^{* *}$ & 0.025 \\
\hline (Upper/Intermediate vs. Lower Track) & Matched & 0.894 & 0.918 & -0.023 & 0.052 \\
\hline Latest Enrollment & Unmatched & 0.500 & 0.598 & $-0.098^{*}$ & 0.053 \\
\hline (Upper vs. Intermediate/Lower Track) & Matched & 0.519 & 0.478 & 0.041 & 0.084 \\
\hline \# Observations Total & & & 502 & & \\
\hline \# Observations On Support & & & 492 & & \\
\hline
\end{tabular}




\section{Appendix}

Table A1: Summary of Matching Quality (Full Sample)

\begin{tabular}{lcc}
\hline & Before Matching & After Matching \\
\hline Mean Standardized Difference & 25.673 & 5.406 \\
Median Standardized Difference & 21.247 & 4.230 \\
Pseudo- $R^{2}$ & 0.212 & 0.020 \\
\hline Source: SOEP, own calculations.
\end{tabular}

Figure A1: Distribution of Propensity Scores (Full Sample)

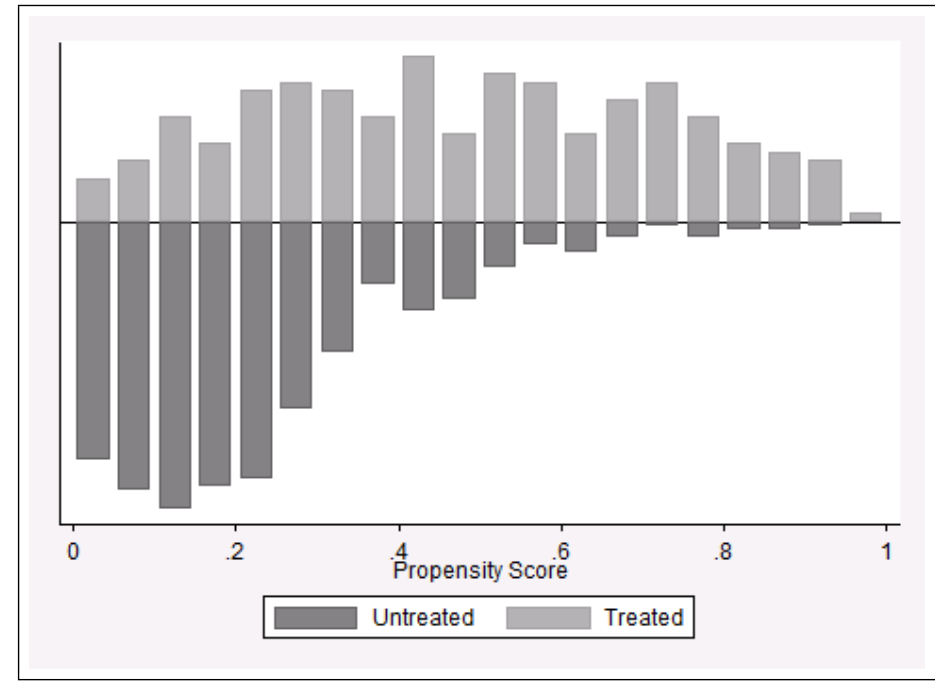

Source: SOEP, own calculations.

Note: Treated: migrant children; untreated: native children. 